\title{
Interrelation between Alterations in Pulmonary Mechanics and Hemodynamics in Acute Myocardial Infarction
}

\author{
Benjamin Interiano, Richard W. Hyde, Morrison Hodges, and \\ PAUL N. YU \\ From the Pulmonary Disease and Cardiology Units, Department of Medicine, \\ University of Rochester School of Medicine, Rochester, New York 14642
}

\begin{abstract}
A B S T R A C T Pulmonary mechanics were evaluated in 30 patients with acute myocardial infarction by measuring forced expiratory flow rates and total pulmonary resistance $\left(R_{T}\right)$ with the oscillometric method at the resonant frequency of the chest $(6-8)$ cycle/s). During the first 3 days after infarction, forced expiratory volume $(\mathrm{FEV})$ and forced mid-expiratory flow rate $\left(\mathrm{FEF}_{25-75} \%\right)$ were $69 \%$ and $60 \%$ of predicted values, respectively. 10 or more wk later these values were $95 \%$ and $91 \%$. Initially, $\mathrm{R}_{\mathbf{T}}$ was $52 \%$ greater than predicted, but was only $4 \%$ greater 10 or more wk later. In 11 patients $R_{T}$ was measured at both resonant frequency and at 3 cycle $/ \mathrm{s}$. Five of these patients had no clinical signs of heart failure, but nine had abnormally high values of pulmonary artery pressure, "wedge" pressure and pulmonary extravascular water volume. All of these patients recovered. Initially, $\mathrm{R}_{\mathbf{T}}$ at resonance was $50 \%$ and $\mathrm{R}_{\mathbf{T}}$ at 3 cycle/s was $130 \%$ greater than predicted values. $2-3 \mathrm{wk}$ later these figures were $-3 \%$ and $+6 \%$ of those predicted, respectively. At $10 \mathrm{wk}$ or more, significant frequency dependence of $\mathrm{R}_{\mathbf{T}}$ had disappeared ( $\mathrm{R}_{\mathbf{T}}$ at 3 cycle/s was $7 \%$ greater than $R_{\mathbf{r}}$ at resonance). Isoproterenol inhalation in six patients caused no change in flow rates, $R_{T}$ at resonance, or $R_{r}$ at 3 cycle/s. $R_{r}$ at resonance and at 3 cycle/s, FEV, and $\mathrm{FEF}_{25-75 \%}$ correlated significantly with the pulmonary vascular pressures. Patients with more marked arterial hypoxia and larger values for ex-
\end{abstract}

This work was presented in part at the jointly sponsored Pulmonary Meeting of the American Federation for Clinical Research and the American Society for Clinical Investigation in Atlantic City, New Jersey, on 30 April 1972.

This work was performed during Dr. Interiano's tenure as a Pulmonary Fellow of the Finger Lakes Tuberculosis and Respiratory Disease Association, and Dr. Hyde's tenure as an Established Investigator of the American Heart Association, with partial support from the Southern Tier Heart Association.

Received for publication 27 Scptember 1972 and in revised form 15 March 1973. travascular water volume had greater elevations of $R_{T}$ and depression of $\mathrm{FEF}_{25-75} \%$, but linear correlations were not significant. Clinical signs of congestive heart failure significantly correlated with a fall in FEV and $\mathrm{FEF}_{25-75 \% \text {, }}$ the development of frequency dependence of $R_{T}$, and elevation of the pulmonary wedge pressure. The initial elevation of $R_{T}$ and low flow rates indicate a modest degree of airway obstruction in acute myocardial infarction. Lack of response to isoproterenol suggests that bronchial muscular constriction is not a major factor. Frequency dependence of $R_{\mathbf{T}}$ accompanied by elevated pulmonary vascular pressures and extravascular water volume indicates that pulmonary congestion causes the development of uneven time constants in the airways. Vascular engorgement and interstitial edema from elevated vascular pressures causing narrowing of the peripheral airways and closure of collateral airways could account for the above findings.

\section{INTRODUCTION}

Hypoxemia is a common finding in patients after acute myocardial infarction (1-6). Determination of arterial oxygen pressure $\left(\mathrm{PO}_{2}\right)$ while patients breathe air or $100 \% \mathrm{O}_{2}$, as well as measurements of the physiological dead space, indicate that this hypoxemia results from shunting of blood past unventilated alveoli and uneven distribution of pulmonary ventilation to pulmonary perfusion (7-10). In contrast, alveolar hypoventilation is uncommon and, in fact, arterial $\mathrm{PCO}_{2}$ is frequently lower than normal. These patients show little or no impairment in carbon monoxide-diffusing capacity, so that hypoxemia usually cannot be attributed to "alveolar-capillary block" (11).

The present study was undertaken to define more clearly changes in pulmonary mechanics in patients with acute myocardial infarction. Alterations in lung mechanics 
were correlated with clinical status, roentgenograms of the chest, arterial blood gas analyses, hemodynamic alterations, and measurements of the pulmonary extravascular water volume. The data indicate that moderate alterations in pulmonary mechanics coincide with subclinical abnormalities in pulmonary hemodynamics. More marked pulmonary function abnormalities were seen in patients with clinical, hemodynamic, and radiological evidence of pulmonary congestion.

\section{METHODS}

Selection of patients. 32 patients admitted to the Myocardial Infarction Research Unit at the University of Rochester Medical Center were studied. The diagnosis of acute myocardial infarction was established on the basis of history, serial enzyme changes, and characteristic electrocardiographic changes. All patients showed the development of pathological $Q$ waves accompanied by evolutionary changes in the ST segments and $T$ waves. To avoid confusion of abnormalities secondary to chronic obstructive lung disease with changes caused by myocardial infarction, two patients with evidence of more than moderate airway obstruction 3-10 wk after infarction were excluded. Forced expiratory volume in one $\mathrm{s}\left(\mathrm{FEV}_{1}\right)^{1}$ of $55 \%$ of the predicted value, or less, was used to identify these patients. Mean age of the patients accepted for study was $56 \mathrm{yr}$ with a range from 34 to $72 \mathrm{yr}$. Eight of the subjects (29\%) did not smoke. Three of the subjects $(10 \%)$ were women. Four patients died 20-180 days after onset of symptoms. None of the patients died while in the Myocardial Infarction Research Unit.

Each patient was placed into one of four clinical classes with respect to left ventricular function, as follows: class I, no signs of left ventricular dysfunction; class II, a third heart sound ("gallop") and basal pulmonary rales; class III, pulmonary edema; class IV, shock. Signs of left ventricular failure observed on roentgenograms of the chest were classified by the method described by $\mathrm{McHugh}$, Forrester, Adler, Zion, and Swan (12), namely, absent, labeled class 0 ; minimal, labeled class I, showing increased blood flow to the upper zones, pulmonary vascular blurring, and hilar haze; moderate, labeled class II, showing marked increase in the outer zone vessels and periacinal rosette formation; and severe, labeled class III, showing diffuse pulmonary infiltrates.

All the patients were studied during the first 3 days after myocardial infarction (acute studies); 19 patients had studies of pulmonary mechanics performed 2-3 wk later (early follow-up); and 8 patients were again studied 10 or more wk later (late follow-up). In order to appraise the validity of using the normal values for forced expiratory flow rates (FEF) recently published by Morris, Koski, and Johnson (13), measurements were obtained from 10 normal subjects, 30-58 yr old (mean $43 \mathrm{yr}$ ), and from 5 patients, 37-62 yr old (mean $50 \mathrm{yr}$ ) who had been hospitalized with documented myocardial infarction 1 or more

${ }^{1}$ Abbreviations used in this paper: ASHD, arteriosclerotic heart disease; FDI, frequency dependence index; FEF,

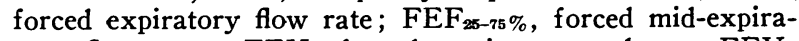
tory flow rate; $\mathrm{FEV}$, forced expiratory volume; $\mathrm{FEV}_{1}$, $\mathrm{FEV}$ in one s; FRC, functional residual capacity ; $\mathrm{pO}_{2}$, oxygen pressure; $R_{T}$, total pulmonary resistance; $R_{R E S}, \cdot R_{T}$ observed at the resonant frequency; $R_{3}, R_{T}$ at 3 cycle/s.

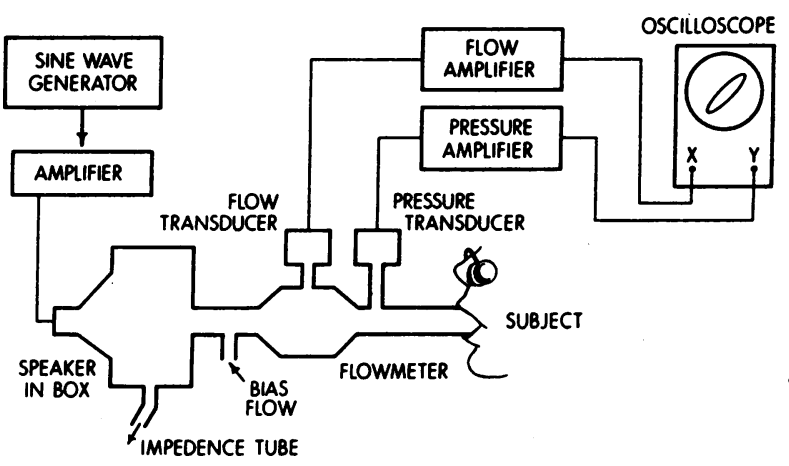

Figure 1 Diagram of apparatus used to measure pulmonary resistance with the forced oscillometric technique. The speaker generates bidirectional sine wave airflow at frequencies that can be varied from 3 to $9 \mathrm{cycle} / \mathrm{s}$. This airflow is superimposed on the subject's normal breathing pattern. Flow and pressure at the mouth are recorded on the $\mathbf{x}$ and $\mathbf{y}$ axes of the oscilloscope. Resistance is then a function of the slope of the line connecting the extremes of the loop on the flow axis. Support of the cheeks with the hands did not significantly alter the observed value of $\mathbf{R}_{\mathbf{T}}$ so that this procedure was not used in this study.

yr previously. Initial measurements were obtained with subjects in bed in the sitting position. Follow-up studies were obtained while subjects sat in a chair with the feet elevated by an additional chair of equal height. FEF was

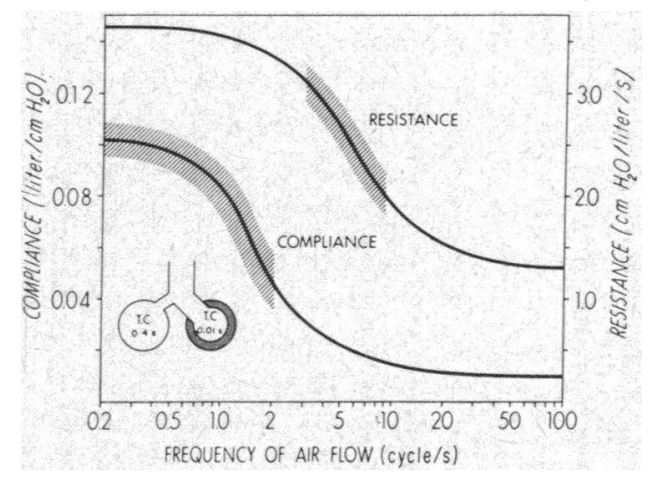

FIGURE 2 Diagram of effect of uneven distribution of airway time constants upon measured values of pulmonary compliance and resistance. In this model one airway was assumed to have a compliance of 0.1 liter $/ \mathrm{cm} \mathrm{H}_{2} \mathrm{O}$ and a resistance of $4 \mathrm{~cm} / \mathrm{liter} / \mathrm{s}$. Values in the other airway were 0.005 liter $/ \mathrm{cm} \mathrm{H}_{2} \mathrm{O}$ and $2 \mathrm{~cm} /$ liter $/ \mathrm{s}$. Since the time constant of an airway is the product of its resistance and compliance, one airway would have a time constant of 0.4 $\mathrm{s}$ and the other $0.01 \mathrm{~s}$. From the equations published by Otis and co-workers (18) the compliance and resistance at any frequency of airflow can be calculated. Note that both values fall with increasing frequency but resistance falls at a higher frequency. The true value of compliance is approached at low frequencies while the minimum value of resistance is reached at high frequencies. The shaded areas represent the approximate frequencies at which it is practical to make measurements in man. (TC = time constant). 
TABLE I

FEF and Pulmonary Resistance in Patients with Acute Myocardial Infarction (MI)

\begin{tabular}{|c|c|c|c|c|c|c|c|c|c|}
\hline Patient & $\begin{array}{c}\text { Day } \\
\text { post-MI }\end{array}$ & Age & FEV & $\begin{array}{c}\% \\
\text { predicted } \\
\text { FEV }\end{array}$ & $\mathrm{FEV}_{1}$ & $\begin{array}{c}\% \text { FEV }_{1} / \\
\text { FEV }\end{array}$ & $\mathrm{FEF}_{2 b-76} \%$ & $\begin{array}{c}\% \\
\text { predicted } \\
\text { FEF }_{26-76} \%\end{array}$ & $\mathbf{R}_{\mathbf{T}}$ \\
\hline & & & $m l$ & & $m l$ & & liter & & $\begin{array}{c}\mathrm{cm} \mathrm{H}_{2} \mathrm{O} / \\
\text { liler } / \mathrm{s}\end{array}$ \\
\hline \multirow[t]{3}{*}{ H. G. } & 2 & 55 & 2,990 & 77 & 2,380 & 80 & 2.0 & 66 & 2.5 \\
\hline & 19 & & 3,880 & 98 & 3,050 & 79 & 3.3 & 106 & 2.7 \\
\hline & $1 \mathrm{yr}$ & & 3,470 & 92 & 2,920 & 80 & 4.1 & 130 & 1.2 \\
\hline \multirow[t]{3}{*}{ W. J. } & 4 & 55 & 2,370 & 57 & 1,720 & 77 & 1.5 & 50 & \\
\hline & 19 & & 2,820 & 60 & 2,170 & 76 & 2.0 & 67 & \\
\hline & $1 \mathrm{yr}$ & & 3,270 & 84 & 2,400 & 80 & 2.2 & 73 & 2.0 \\
\hline C. P. & 3 & 68 & 3,240 & 83 & 1,950 & 60 & 1.4 & 46 & \\
\hline \multirow[t]{3}{*}{ R. R. } & 3 & 54 & 3,560 & 89 & 2,470 & 73 & 2.4 & 80 & 2.7 \\
\hline & 23 & & 4,080 & 102 & 2,980 & 73 & 2.7 & 90 & 2.9 \\
\hline & $8 \mathrm{mo}$ & & 4,270 & 106 & 3,080 & 73 & 2.6 & 86 & 1.6 \\
\hline \multirow[t]{2}{*}{ D. L. } & 2 & 46 & 4,070 & 95 & 3,040 & 74 & 3.6 & 100 & \\
\hline & 20 & & 4,300 & 100 & 3,430 & 80 & 5.0 & 138 & \\
\hline \multirow[t]{2}{*}{ H. Mc. } & 3 & 52 & 2,800 & 80 & 2,080 & 74 & 1.3 & 50 & 2.8 \\
\hline & 21 & & 3,020 & 86 & 2,170 & 71 & 1.6 & 62 & 3.1 \\
\hline \multirow{5}{*}{$\begin{array}{l}\text { D. D. } \\
\text { F. B. } \\
\text { S. L. }\end{array}$} & 2 & 65 & 2,260 & 58 & 1,700 & 75 & 1.4 & 46 & \\
\hline & 2 & 68 & 3,490 & 89 & 2,320 & 66 & 1.3 & 43 & 2.3 \\
\hline & 3 & 67 & 3,185 & 82 & 2,250 & 70 & 1.7 & 56 & 2.4 \\
\hline & 18 & & 3,670 & 89 & 2,600 & 73 & 2.2 & 73 & \\
\hline & $7 \mathrm{mo}$ & & 3,640 & 88 & 2,780 & 76 & 2.1 & 70 & 1.9 \\
\hline C. B. & 3 & 57 & 1,990 & 65 & 1,400 & 70 & 1.2 & 46 & 2.5 \\
\hline E. S. & 2 & 58 & 3,620 & 93 & 2,590 & 71 & 2.3 & 76 & 3.0 \\
\hline I. S. & 4 & 64 & 1,510 & 57 & 1,120 & 74 & 1.5 & 57 & 1.8 \\
\hline J. H. & 3 & 63 & 4,360 & 86 & 2,890 & 66 & 1.8 & 50 & \\
\hline G. D. & 3 & 52 & 3,560 & 72 & 2,590 & 73 & 2.0 & 66 & 2.4 \\
\hline \multirow[t]{2}{*}{ F. J. } & 3 & 56 & 3,530 & 74 & 2,530 & 75 & 1.9 & 63 & \\
\hline & 21 & & 3,920 & 83 & 2,770 & 75 & 1.8 & 60 & \\
\hline \multirow[t]{2}{*}{ J. R. } & 4 & 57 & 2,160 & 54 & 1,490 & 69 & 1.4 & 46 & \\
\hline & 21 & & 3,080 & 77 & 2,100 & 68 & 1.8 & 60 & \\
\hline A. L. & 2 & 62 & 3,520 & 86 & 2,450 & 70 & 1.6 & 53 & \\
\hline J. M. & 4 & 57 & 2,590 & 70 & 1,620 & 63 & 1.2 & 40 & \\
\hline H. B. & 3 & 50 & 3,510 & 83 & 2,260 & 64 & 1.6 & 53 & \\
\hline \multirow[t]{3}{*}{ V. W. } & 3 & 50 & 3,420 & 67 & 2,690 & 78 & 2.7 & 75 & 1.5 \\
\hline & 15 & & 3,920 & 77 & 3,250 & 83 & 4.3 & 126 & 1.0 \\
\hline & 90 & & 5,000 & 98 & 3,800 & 76 & 3.4 & 100 & 1.3 \\
\hline \multirow[t]{2}{*}{ H. O. } & 3 & 72 & 3,060 & 66 & 2,440 & 80 & 2.1 & 60 & 1.9 \\
\hline & 15 & & 3,380 & 74 & 2,620 & 77 & 2.0 & 58 & 1.0 \\
\hline \multirow[t]{3}{*}{ E. $\mathrm{H}_{\text {. }}$} & 3 & 49 & 4,210 & 81 & 3,450 & 82 & 3.7 & 100 & 2.2 \\
\hline & 17 & & 4,430 & 85 & 3,530 & 80 & 3.3 & 90 & 1.7 \\
\hline & 72 & & 4,560 & 88 & 3,650 & 80 & 3.7 & 100 & 1.7 \\
\hline \multirow[t]{3}{*}{ D. R. } & 3 & 34 & 3,560 & 69 & 2,700 & 76 & 2.4 & 57 & 1.6 \\
\hline & 19 & & 4,300 & 84 & 3,660 & 85 & 3.8 & 90 & 1.8 \\
\hline & 86 & & 5,080 & 100 & 4,000 & 80 & 4.3 & 100 & 1.6 \\
\hline \multirow[t]{2}{*}{ C. St. } & 1 & 64 & 1,510 & 42 & 1,200 & 80 & 1.2 & 47 & 4.1 \\
\hline & 19 & & 2,290 & 64 & 1,980 & 86 & 2.7 & 100 & 2.2 \\
\hline \multirow[t]{3}{*}{ F. M. } & 2 & 44 & 4,430 & 94 & 3,670 & 83 & 4.0 & 100 & 1.5 \\
\hline & 20 & & 4,450 & 94 & 3,700 & 85 & 4.0 & 100 & 1.4 \\
\hline & 120 & & 4,480 & 95 & 3,700 & 79 & 4.0 & 100 & 1.6 \\
\hline
\end{tabular}

1996 B. Interiano, R. W. Hyde, M. Hodges, and P. N. Yu 
TABLE I-(Continued)

\begin{tabular}{|c|c|c|c|c|c|c|c|c|c|}
\hline Patient & $\begin{array}{c}\text { Day } \\
\text { post-MI }\end{array}$ & Age & FEV & $\begin{array}{c}\% \\
\text { predicted } \\
\text { FEV }\end{array}$ & FEV $_{1}$ & $\begin{array}{c}\text { \% FEV } 1 / \\
\text { FEV }\end{array}$ & $\mathrm{FEF}_{26-78} \%$ & $\begin{array}{c}\% \\
\text { predicted } \\
\text { FEF }_{26-76} \%\end{array}$ & $\mathbf{R}_{\mathbf{T}}$ \\
\hline & & & $m l$ & & $m l$ & & liter & & $\begin{array}{c}\mathrm{cm} \mathrm{H}_{2} \mathrm{O} / \mathrm{I} \\
\text { liter } / \mathrm{s}\end{array}$ \\
\hline S. S. & $\begin{array}{r}3 \\
18\end{array}$ & 59 & $\begin{array}{l}2,480 \\
4,000\end{array}$ & $\begin{array}{l}55 \\
89\end{array}$ & $\begin{array}{l}1,940 \\
3,140\end{array}$ & $\begin{array}{l}78 \\
78\end{array}$ & $\begin{array}{l}2.1 \\
3.0\end{array}$ & $\begin{array}{l}67 \\
98\end{array}$ & $\begin{array}{l}3.6 \\
1.5\end{array}$ \\
\hline E. W. & $\begin{array}{r}3 \\
17\end{array}$ & 48 & $\begin{array}{l}3,220 \\
4,540\end{array}$ & $\begin{array}{l}58 \\
83\end{array}$ & $\begin{array}{l}2,380 \\
3,420\end{array}$ & $\begin{array}{l}74 \\
75\end{array}$ & $\begin{array}{l}1.7 \\
2.5\end{array}$ & $\begin{array}{l}46 \\
68\end{array}$ & $\begin{array}{l}3.7 \\
1.2\end{array}$ \\
\hline J. G & $\begin{array}{r}3 \\
19\end{array}$ & 66 & $\begin{array}{l}2,380 \\
3,320\end{array}$ & $\begin{array}{l}69 \\
97\end{array}$ & $\begin{array}{l}1,940 \\
2,700\end{array}$ & $\begin{array}{l}81 \\
81\end{array}$ & $\begin{array}{l}1.8 \\
2.8\end{array}$ & $\begin{array}{r}65 \\
100\end{array}$ & $\begin{array}{l}2.1 \\
1.7\end{array}$ \\
\hline M. S. & $\begin{array}{r}2 \\
20\end{array}$ & 64 & $\begin{array}{l}1,990 \\
2,700\end{array}$ & $\begin{array}{l}59 \\
80\end{array}$ & $\begin{array}{l}1,540 \\
2,240\end{array}$ & $\begin{array}{l}83 \\
83\end{array}$ & $\begin{array}{l}1.5 \\
2.2\end{array}$ & $\begin{array}{l}60 \\
88\end{array}$ & $\begin{array}{l}2.4 \\
1.8\end{array}$ \\
\hline R. B. & $\begin{array}{r}3 \\
19\end{array}$ & 68 & $\begin{array}{l}1,700 \\
2,800\end{array}$ & $\begin{array}{l}50 \\
80\end{array}$ & $\begin{array}{r}940 \\
1,700\end{array}$ & $\begin{array}{l}55 \\
69\end{array}$ & $\begin{array}{l}1.2 \\
1.8\end{array}$ & $\begin{array}{l}45 \\
68\end{array}$ & $\begin{array}{l}2.9 \\
2.0\end{array}$ \\
\hline $\begin{array}{l}\text { Mean } \\
\text { values }\end{array}$ & $\begin{array}{l}1-4 \text { days } \\
2-3 \text { wk } \\
10 \text { wk or more }\end{array}$ & $\begin{array}{l}57 \\
51 \\
55\end{array}$ & $\begin{array}{l}2,900 \\
3,860^{*} \\
4,220^{*}\end{array}$ & $\begin{array}{l}69 \\
84^{*} \\
95^{*}\end{array}$ & $\begin{array}{l}2,120 \\
2,830^{*} \\
3,290^{*}\end{array}$ & $\begin{array}{l}73 \\
74 \\
77\end{array}$ & $\begin{array}{l}1.9 \\
2.8^{*} \\
3.3^{*}\end{array}$ & $\begin{array}{l}60 \\
88^{*} \\
91^{*}\end{array}$ & $\begin{array}{l}2.5 \\
1.8 \ddagger \\
1.6 \ddagger\end{array}$ \\
\hline
\end{tabular}

Predicted values for $\mathrm{FEV}$ and $\mathrm{FEF}_{25-75}$ were obtained from reference $13 . \% \mathrm{FEV}_{1} / \mathrm{FEV}$, percent of FEV during first second. $* \mathrm{P}<0.01$ (compared to $1-4$ days values).

$\ddagger \mathrm{P}<0.05$ (compared to $1-4$ days values).

obtained with a Stead-Wells spirometer ${ }^{2}$ and calculated by the methods described by Morris, Koski, and Johnson (13).

The Committee on Human Investigation of this institution had reviewed and approved the research proposal. Written informed consent for these studies was obtained from each patient.

Total pulmonary resistance $\left(R_{T}\right)$ was measured with the forced oscillometric technique previously described by Fisher, DuBois, and Hyde (14), with the following modifications: mechanical design of the apparatus closely followed the specifications reported by Hyatt, Zimmerman, Peters, and Sullivan (15), thereby permitting the patient to breathe comfortably during the procedure (Fig. 1). An additional volume of $18 \mathrm{ml}$ of air contained in 1 -inch rubber tubing was connected with a " $T$ " to the smaller-sized chamber of the differential pressure manometer ${ }^{3}$ attached to the pneumotachygraph in order to give adequate frequency response at $9 \mathrm{cycle} / \mathrm{s}$. $R_{T}$ was measured at the patient's resonant frequency $(5-8 \mathrm{cycle} / \mathrm{s})$ and in 11 of these patients at $3,5,7$, and 9 cycle/s. At 3 and 9 cycle/s the display of mouth pressure and flow on the two axes of the $x-y$ storage oscilloscope frequently showed considerable "looping." If looping was present, a line was drawn between the extremes of flow of the individual loop and the angle determined. As described by Frank, Mead, and Whittenberger. (16), the tangent of this line is proportional to $R_{T}$. Theoretical aspects of this method have been discussed in detail elsewhere (Fig. 2 [14-18]). At each frequency the mean of 3-7 determinations obtained at functional residual capacity or early in inspiration during normal breathing

${ }^{2}$ Warren E. Collins, Inc., Braintree, Mass.

${ }^{8}$ Statham model PM-5 TC $\pm 0.15-350$, Statham Instruments, Inc., Hato Rey, Puerto Rico. Because gas volume on the inner side of the sensing membrane of this gauge is much larger than the volume on the outer side, the latter volume must be increased to obtain a flat frequency response up to 10 cycle/s. was recorded. Power to the loudspeaker supplying the oscillating airflow was adjusted to give a flow rate at the mouth that oscillated between +0.5 and -0.5 liter $/ \mathrm{s}$. Narrowing of the glottis could be readily detected by a sudden increase in $R_{T}$. Control values for $R_{T}$ were obtained from the 15 subjects previously mentioned.

In six patients, spirometry and pulmonary resistance were measured before and after inhalation of $0.5 \%$ isoproterenol in four deep breaths over a 10-min period delivered by a replica of a Dautrebande D-30 nebulizer." This method of administration of isoproterenol produces improvement in FEF in patients with asthma (19). Arterial blood gases were analyzed by previously described methods (19). Right ventricular, pulmonary artery, and pulmonary wedge pressures were monitored with a Swan-Ganz catheter (20). Cardiac outputs were performed by the indocyanine green dye dilution technique, with injection into the main pulmonary artery and sampling from the brachial artery. From the same injection and sampling site, pulmonary extravascular water volume was determined by the double isotope dilution technique using radio-iodinated serum albumin and tritiated water as indicators (21). Details of the techniques for measuring cardiac output, vascular pressures, and pulmonary extravascular water volume will be reported separately.

\section{RESULTS}

Spirometry. During the first 4 days after acute myocardial infarction, FEF was reduced in the majority of patients (Table I). The mean forced expiratory volume (FEV) was $69 \%$ of predicted, compared to $95 \%$ in 10 normal subjects $(P<0.01)$ and $90 \%$ in 5 patients with stable arteriosclerotic heart disease (ASHD) $(P<$

"Manufactured by the R. E. Reynolds Co., Rochester, N. Y. 

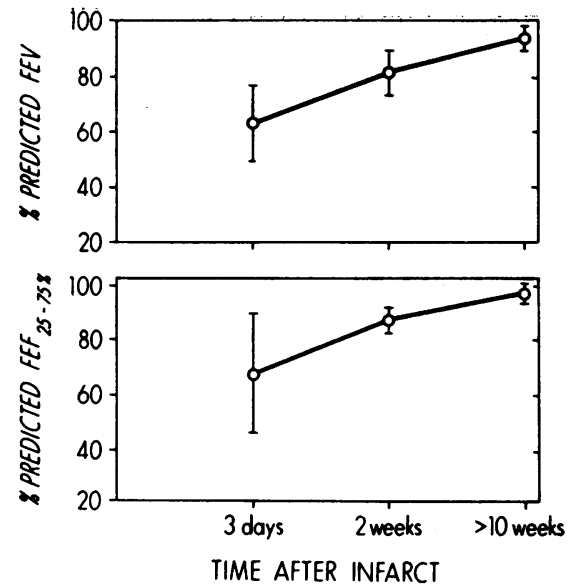

Figure 3 Mean values and standard deviation for the percent of FEV and $\mathrm{FEF}_{25-75} \%$ measured 3 days, 2-3 wk, and more than 10 wk after acute myocardial infarction.

TABLE II

Pulmonary Resistance at Different Frequencies in Patients with Acute Myocardial Infarction (MI)

\begin{tabular}{|c|c|c|c|c|c|c|c|c|}
\hline Patient & $\begin{array}{c}\text { Day } \\
\text { post- } \\
\text { MI }\end{array}$ & fRES & $\mathbf{R}_{\mathbf{T}}$ & $\mathbf{R}_{3}$ & $\mathbf{R}_{\mathbf{6}}$ & $\mathbf{R}_{7}$ & $R_{9}$ & FDI \\
\hline & & \multicolumn{2}{|l|}{ cycle/s } & \multicolumn{3}{|c|}{$\mathrm{cm} \mathrm{H}_{2} \mathrm{O} /$ liter $/ \mathrm{s}$} & & \\
\hline \multirow[t]{3}{*}{ V. W. } & 3 & 6 & 1.5 & 2.0 & 1.5 & 1.5 & & 0.17 \\
\hline & 15 & 6 & 1.0 & 1.2 & 1.0 & 0.9 & & 0.10 \\
\hline & 90 & 6 & 1.3 & 1.4 & 1.3 & 1.2 & 1.1 & 0.03 \\
\hline \multirow[t]{2}{*}{ H. O. } & 3 & 6 & 1.9 & 2.4 & 1.9 & 1.9 & & 0.17 \\
\hline & 15 & 7 & 1.1 & 1.5 & 1.1 & 0.9 & & 0.13 \\
\hline \multirow[t]{3}{*}{ E. H. } & 3 & 6 & 2.2 & 3.2 & 2.7 & 2.2 & 2.2 & 0.33 \\
\hline & 17 & 7 & 1.7 & 2.3 & 1.8 & 1.7 & 1.6 & 0.15 \\
\hline & 71 & 7 & 1.7 & 1.9 & 1.8 & 1.6 & 1.6 & 0.05 \\
\hline \multirow[t]{3}{*}{ D. R. } & 3 & 6 & 1.6 & 3.2 & 1.9 & 1.6 & 1.5 & 0.53 \\
\hline & 19 & 6 & 1.8 & 1.9 & 1.8 & 1.8 & 1.7 & 0.03 \\
\hline & 86 & 7 & 1.6 & 1.6 & 1.5 & 1.5 & 1.5 & 0.00 \\
\hline \multirow[t]{2}{*}{ C. St. } & 2 & 7 & 4.1 & 7.9 & 5.5 & 3.9 & 3.5 & 0.95 \\
\hline & 19 & 7 & 2.2 & 2.4 & 2.2 & 2.0 & 1.9 & 0.05 \\
\hline \multirow[t]{3}{*}{ F. $M$. } & 2 & 6 & 1.5 & 2.4 & 2.0 & 1.6 & 1.5 & 0.30 \\
\hline & 20 & 6 & 1.4 & 1.8 & 1.5 & 1.4 & 1.4 & 0.13 \\
\hline & 120 & 7 & 1.5 & 1.6 & 1.6 & 1.4 & 1.4 & 0.02 \\
\hline \multirow[t]{2}{*}{ S. S. } & 3 & 7 & 3.6 & 4.9 & 4.0 & 3.5 & 3.2 & 0.33 \\
\hline & 18 & 7 & 1.5 & 1.6 & 1.5 & 1.4 & 1.4 & 0.02 \\
\hline \multirow[t]{2}{*}{ E. W. } & 3 & 6 & 3.7 & 5.5 & 4.1 & 3.6 & 3.1 & 0.56 \\
\hline & 17 & 6 & 1.2 & 1.5 & 1.3 & 1.2 & 1.1 & 0.10 \\
\hline \multirow[t]{2}{*}{ J. G. } & 3 & 7 & 2.1 & 3.5 & 2.3 & 2.1 & 1.8 & 0.35 \\
\hline & 19 & 7 & 1.7 & 2.0 & 1.8 & 1.7 & 1.6 & 0.08 \\
\hline \multirow[t]{2}{*}{ M. S. } & 2 & 7 & 2.4 & 4.9 & 2.7 & 2.4 & 2.3 & 0.62 \\
\hline & 20 & 7 & 1.8 & 2.2 & 1.9 & 1.8 & 1.6 & 0.10 \\
\hline \multirow[t]{2}{*}{ R. B. } & 3 & 7 & 2.9 & 4.9 & 3.5 & 2.9 & 2.8 & 0.50 \\
\hline & 19 & 7 & 2.0 & 2.5 & 2.1 & 2.0 & 1.9 & 0.12 \\
\hline \multirow[t]{3}{*}{ Mean } & $2-3$ days & & 2.5 & 4.1 & 2.9 & 2.5 & 2.4 & 0.44 \\
\hline & $2-3$ wk & & $1.6 *$ & $1.9 *$ & $1.6 *$ & $1.5^{*}$ & $1.6 \ddagger$ & $0.09 \ddagger$ \\
\hline & $10-17 \mathrm{wk}$ & & $1.5^{*}$ & $1.6 *$ & $1.6 *$ & $1.4^{*}$ & $1.4 \ddagger$ & $0.03 *$ \\
\hline
\end{tabular}

fRES frequency during resonance. $R_{\mathbf{3}}, R_{\mathbf{3}}, \mathbf{R}_{\mathbf{7}}, \mathbf{R}_{\mathbf{9}}$, resistance measured at 3 , 5,7 , and 9 cycles.

$* \mathrm{P}<0.05$. $¥ \mathrm{P}<0.01$ (compared to $2-3$ days values).
0.05). The mean forced mid-expiratory flow rate $\left(\mathrm{FEF}_{25-75 \%}\right)$ was $60 \%$ of that predicted, compared to control values of $95 \%$ in normal $(P<0.01)$ and $86 \%$ in ASHD $(P<0.02)$.

When spirometric studies were repeated 2-3 wk later in 19 patients, mean FEV increased from $69 \%$ to $84 \%$ of that predicted. This change was significant $(P<0.01)$. Mean $\mathrm{FEF}_{25-75 \%}$ increased from $60 \%$ to $88 \%$ of predicted $(P<0.01)$ (Fig. 3). In the eight patients studied 10 or more wk after acute infarction, mean $\mathrm{FEV}$ was $95 \%$ and $\mathrm{FEF}_{25-75 \%}$ was $90 \%$ of the predicted values. When compared to results obtained during the first 4 days, these changes were significant at the $1 \%$ level.

FEV and $\mathrm{FEF}_{25-75} \%$ measured 2-3 wk after acute myocardial infarction did not significantly differ from the control values $(P<0.3$ and 0.2 , respectively).

Total pulmonary resistance $\left(R_{T}\right)$. $R_{T}$ was measured at the resonant frequency of the thorax (5-7 cycle/s) in 21 patients during the first 4 days after acute infarction. Mean $\mathrm{R}_{\mathrm{r}}$ at resonance was $2.5 \mathrm{~cm} \mathrm{H} \mathrm{H}_{2} \mathrm{O} /$ liter/s compared to values in the control patients of $1.6 \mathrm{~cm} \mathrm{H} \mathrm{H}_{2} \mathrm{O} /$ liter/s $(P<0.02)$. 3 wk later, mean $\mathrm{R}_{\mathrm{T}}$ at resonance was 1.8 ,

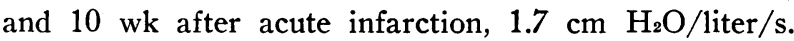
Compared to the initial values determined in these subjects, these changes were significant $(P<0.05)$. In 11 of these patients the pulmonary resistance was also measured at frequencies of $3,5,7$, and $9 \mathrm{cycle} / \mathrm{s}$ (Table II). No significant difference was seen between the resistance measured at resonant frequency and $9 \mathrm{cycle} / \mathrm{s}(P>0.2)$, but a striking elevation of resistance at a frequency of

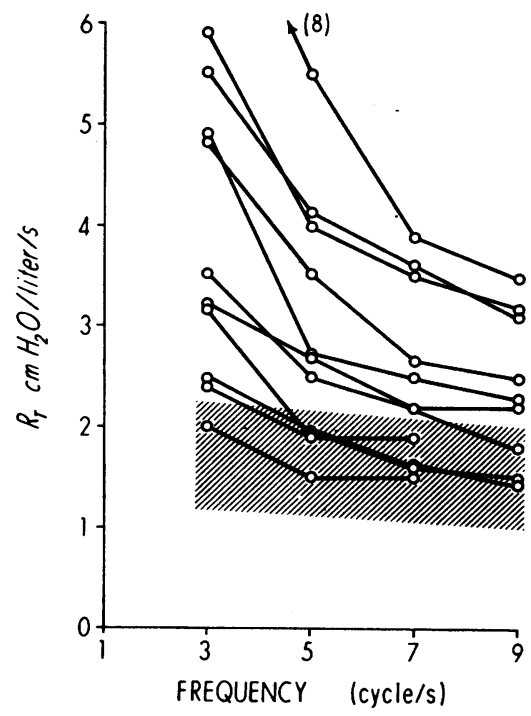

Figure $4 R_{T}$ measured at 3, 5, 7, and 9 cycle/s 1-3 days after acute myocardial infarction. The shaded area represents the range observed in control subjects. Note that most of the patients show an increased resistance at 3 cycle/s. 


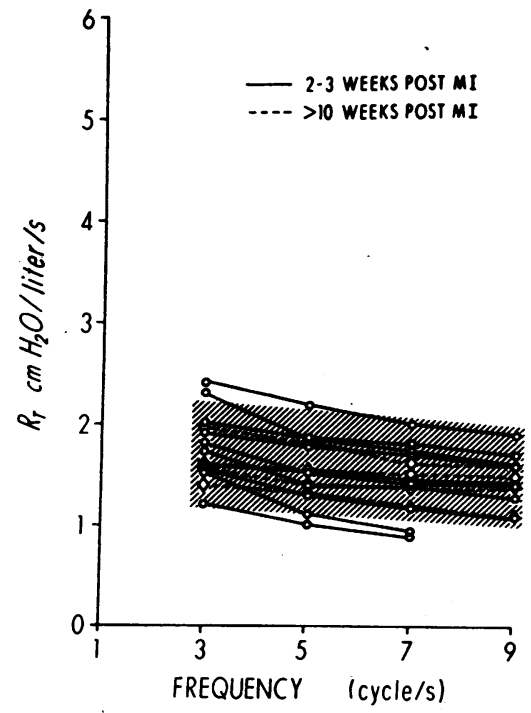

FIGURE 5 Rr measured at 3, 5, 7, and 9 cycle/s $2-3$ wk and over $10 \mathrm{wk}$ after acute myocardial infarction. The shaded area is the range observed on control subjects. Note that the frequency dependence of the resistance has almost completely disappeared.

3 cycle/s was observed. The mean $R_{\mathrm{r}}$ at $3 \mathrm{cycle} / \mathrm{s}$ was 4.1 $\mathrm{cm} \mathrm{H}_{2} \mathrm{O}$ liter/s compared to 2.5 for the $\mathrm{R}_{\mathrm{r}}$ at resonance $(P<0.02)$ (Fig. 4$)$.

2-3 wk later, $\mathrm{R}_{\mathbf{T}}$ at $3 \mathrm{cycle} / \mathrm{s}$ fell to $1.9 \mathrm{~cm} \mathrm{H} \mathrm{H}_{2} \mathrm{O} / \mathrm{liter} / \mathrm{s}$ $(P<0.01)$ and did not differ significantly from the resistance measured at higher frequencies $(P>0.2) .10$ or more wk after acute infarction the mean $R_{T}$ at 3 cycle/s was $1.6 \mathrm{~cm} \mathrm{H} \mathrm{H}_{2} \mathrm{O} /$ liter/s, almost identical to the predicted value of $1.7 \mathrm{~cm} \mathrm{H} \mathrm{H}_{2} \mathrm{O} /$ liter $/ \mathrm{s}(P>0.3)$ (Fig. 5).

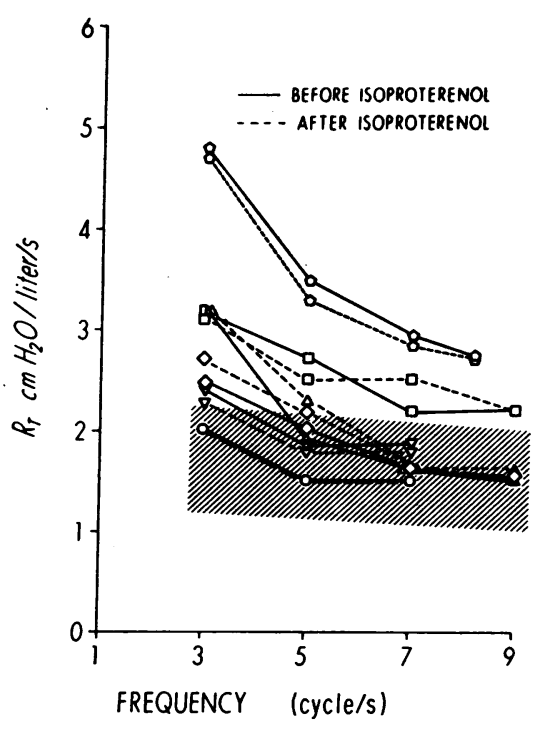

FIGURE $6 R_{T}$ measured at 3, 5, 7, and 9 cycle/s before (continuous line) and after (broken line) isoproterenol inhalation. Each symbol represents a different patient. Note the absence of change in frequency dependence of the resistance after inhalation of isoproterenol.

Effect of isoproterenol on pulmonary mechanics. After the inhalation of isoproterenol, no consistent change in FEF, $R_{\mathbf{T}}$ at resonance, or $R_{\mathbf{T}}$ at other frequencies was observed in any patient (Fig. 6, Table III).

Frequency dependence index. In order to have a single numerical expression of the frequency dependence of resistance that could be readily compared to other data obtained in these patients, a frequency dependence index (FDI) was devised. It is defined as the difference be-

TABLE III

Isoproterenol Studies

\begin{tabular}{|c|c|c|c|c|c|c|c|c|c|c|}
\hline Patient & & $\begin{array}{l}\text { Predicted } \\
\% \text { FEV }\end{array}$ & $\begin{array}{c}\text { Predicted } \\
\% \text { FEV }\end{array}$ & $\begin{array}{c}\% \\
\text { Predicted } \\
\text { FEF }_{26-76} \%\end{array}$ & $\mathbf{R} \mathbf{T}$ & $\mathbf{R}_{\mathbf{z}}$ & $\mathbf{R}_{\mathbf{b}}$ & $\mathbf{R}_{7}$ & $\mathbf{R}_{\mathbf{0}}$ & FDI \\
\hline V. W. & $\begin{array}{l}\text { Control } \\
\text { Isoproterenol }\end{array}$ & $\begin{array}{l}67 \\
70\end{array}$ & $\begin{array}{l}72 \\
73\end{array}$ & $\begin{array}{l}75 \\
75\end{array}$ & $\begin{array}{l}1.5 \\
1.5\end{array}$ & $\begin{array}{l}2.0 \\
2.0\end{array}$ & $\begin{array}{l}1.5 \\
1.5\end{array}$ & $\begin{array}{l}1.5 \\
1.5\end{array}$ & & $\begin{array}{l}0.17 \\
0.25\end{array}$ \\
\hline H. O. & $\begin{array}{l}\text { Control } \\
\text { Isoproterenol }\end{array}$ & $\begin{array}{l}66 \\
70\end{array}$ & $\begin{array}{l}80 \\
80\end{array}$ & $\begin{array}{l}60 \\
58\end{array}$ & $\begin{array}{l}1.8 \\
1.8\end{array}$ & $\begin{array}{l}2.4 \\
2.3\end{array}$ & $\begin{array}{l}1.9 \\
1.8\end{array}$ & $\begin{array}{l}1.9 \\
1.8\end{array}$ & & $\begin{array}{l}0.20 \\
0.25\end{array}$ \\
\hline E. H. & $\begin{array}{l}\text { Control } \\
\text { Isoproterenol }\end{array}$ & $\begin{array}{l}81 \\
77\end{array}$ & $\begin{array}{l}90 \\
88\end{array}$ & $\begin{array}{l}100 \\
100\end{array}$ & $\begin{array}{l}2.2 \\
2.3\end{array}$ & $\begin{array}{l}3.2 \\
3.1\end{array}$ & $\begin{array}{l}2.7 \\
2.5\end{array}$ & $\begin{array}{l}2.2 \\
2.5\end{array}$ & $\begin{array}{l}2.2 \\
2.2\end{array}$ & $\begin{array}{l}0.33 \\
0.26\end{array}$ \\
\hline D. R. & $\begin{array}{l}\text { Control } \\
\text { Isoproterenol }\end{array}$ & $\begin{array}{l}69 \\
67\end{array}$ & $\begin{array}{l}67 \\
67\end{array}$ & $\begin{array}{l}57 \\
53\end{array}$ & $\begin{array}{l}1.6 \\
1.6\end{array}$ & $\begin{array}{l}3.2 \\
3.2\end{array}$ & $\begin{array}{l}1.9 \\
2.3\end{array}$ & $\begin{array}{l}1.6 \\
1.6\end{array}$ & $\begin{array}{l}1.5 \\
1.6\end{array}$ & $\begin{array}{l}0.53 \\
0.53\end{array}$ \\
\hline F. M. & $\begin{array}{l}\text { Control } \\
\text { Isoproterenol }\end{array}$ & $\begin{array}{l}94 \\
90\end{array}$ & $\begin{array}{l}100 \\
100\end{array}$ & $\begin{array}{l}100 \\
100\end{array}$ & $\begin{array}{l}1.5 \\
1.6\end{array}$ & $\begin{array}{l}2.4 \\
2.7\end{array}$ & $\begin{array}{l}2.0 \\
2.2\end{array}$ & $\begin{array}{l}1.6 \\
1.5\end{array}$ & $\begin{array}{l}1.5 \\
1.5\end{array}$ & $\begin{array}{l}0.29 \\
0.34\end{array}$ \\
\hline R. B. & $\begin{array}{l}\text { Control } \\
\text { Isoproterenol }\end{array}$ & $\begin{array}{l}50 \\
48\end{array}$ & $\begin{array}{l}55 \\
54\end{array}$ & $\begin{array}{l}45 \\
40\end{array}$ & $\begin{array}{l}2.9 \\
2.8\end{array}$ & $\begin{array}{l}4.9 \\
4.8\end{array}$ & $\begin{array}{l}3.5 \\
3.2\end{array}$ & $\begin{array}{l}2.9 \\
2.8\end{array}$ & $\begin{array}{l}2: 9 \\
2.8\end{array}$ & $\begin{array}{l}0.50 \\
0.50\end{array}$ \\
\hline
\end{tabular}

$R_{3}, R_{5}, R_{7}, R_{9}$, resistance measured at $3,5,7$, and 9 cycle $/ \mathrm{s}$.

FDI $=\left(R_{3}-R_{r}\right) \div\left(\nu_{r}-3\right)$ where $\nu_{r}=$ resonant frequency of the chest. For details see text. 


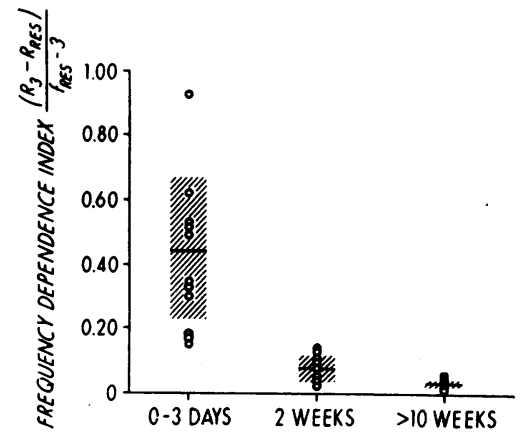

Figure 7 FDI during the first 3 days, 2 wk, and more than $10 \mathrm{wk}$ after acute myocardial infarction. Each circle represents a patient. The horizontal line is the mean value and the shaded area the standard deviation. Note the significant fall in the index, 2 and $10 \mathrm{wk}$ after the infarction.

tween $R_{T}$ at 3 cycle/s $\left(R_{3}\right)$ and $R_{T}$ observed at the resonant frequency $\left(R_{\mathbf{R E S}}\right)$, divided by the difference in the number of cycles between the resonant frequency $\left(f_{\mathrm{RES}}\right)$ and 3 cycle/s or: $F D I=\left(R_{3}-R_{\mathrm{RES}}\right) \div\left(f_{\mathrm{RES}}-3\right)$. During the first 4 days after acute myocardial infarction, all 11 patients studied had an abnormally elevated FDI. Its value was 0.44 compared to 0.05 obtained in 15 control subjects $(P<0.01) .2-3$ wk later the FDI had fallen to 0.09 and did not significantly differ from control values $(P>0.2)$ (Fig. 7 ).

Correlation of alterations in pulmonary mechanics with other findings. The measurements of pulmonary mechanics obtained during the first 3 days after acute myocardial infarction in the 11 patients studied in detail were correlated with measurements of arterial blood gases, pulmonary extravascular water volume, mean pulmonary artery pressure, pulmonary wedge pressure, and pulmonary vascular resistance (Table IV). The FDI showed a significant correlation $(P<0.01)$ to pulmonary artery pressure but not to pulmonary vascular resistance or pulmonary wedge pressure (Table V). Pulmonary resistance measured at $3 \mathrm{cycle} / \mathrm{s}$ correlated with pulmonary artery pressure and pulmonary wedge pressure $(P<0.01)$, but not with pulmonary vascular resistance. FEV showed a similar correlation with the pulmonary vascular pressures $(P<0.01)$, while $\mathrm{FEF}_{25-75 \%}$ showed a less striking correlation $(P<0.05)$.

Although nine patients had abnormally high pulmonary extravascular water volume $\left(>120 \mathrm{ml} / \mathrm{m}^{2}\right)$, and six patients had an arterial oxygen tension less than $70 \mathrm{~mm} \mathrm{Hg}$ while breathing air, no significant linear correlation could be established between these parameters and the degree of abnormality in pulmonary mechanics (Table V).

Clinical and radiological findings. Four patients were in clinical class I, six in class II, and one in class III. 10 of the 11 patients studied in detail during the first 3 days after acute myocardial infarction had roentgenograms of the chest available for study. One patient showed no radiological evidence of left ventricular failure, two patients had minimal changes, five had moderate changes, and two had severe changes. The correlation of the clinical classification with FEV,

TABLE IV

FEV $, R_{3}, F D I$, Arterial Oxygen Tension, Hemodynamic Measurements, Pulmonary Extravascular Water Volumc, Clinical Class, and Radiological Class in Patients with Acute Myocardial Infarction

\begin{tabular}{|c|c|c|c|c|c|c|c|c|c|c|c|}
\hline Patients & $\%$ FEV & $\mathbf{R}_{\mathbf{3}}$ & FDI & $\mathrm{PaO}_{2}$ & PWP & PAP & CI & PVR & PEV & $\begin{array}{l}\text { Clinical } \\
\text { class }\end{array}$ & $\begin{array}{l}\text { Radio- } \\
\text { logical } \\
\text { class }\end{array}$ \\
\hline & & & & $m m \mathrm{Hg}$ & $m m \mathrm{Hg}$ & $m m \mathrm{Hg}$ & $\begin{array}{l}\text { liter } / \\
\min / m^{2}\end{array}$ & $\begin{array}{l}d y n \cdot s \\
\cdot \mathrm{Cm}^{-5}\end{array}$ & $\mathrm{ml} / \mathrm{m}^{2}$ & & \\
\hline V. W. & 67 & 2.0 & 0.17 & 78 & 12 & 20 & 2.53 & 124 & 105 & 1 & - \\
\hline H. O. & 66 & 2.4 & 0.17 & 62 & 7 & 11 & 2.30 & 65 & 180 & 1 & III \\
\hline E. H. & 81 & 3.2 & 0.33 & 69 & 5 & 15 & 3.52 & 106 & 209 & 1 & 0 \\
\hline D. R. & 69 & 3.2 & 0.53 & 77 & 9 & 17 & 4.29 & 69 & 80 & 2 & I \\
\hline C. St. & 42 & 7.9 & 0.95 & 53 & - & 50 & 2.84 & - & 116 & 2 & III \\
\hline F. M. & 94 & 2.4 & 0.30 & 61 & 3 & 10 & 3.02 & 95 & 177 & 1 & I \\
\hline S. S. & 55 & 4.9 & 0.33 & 69 & 18 & 24 & 2.21 & 114 & 132 & 2 & II \\
\hline E. W. & 58 & 5.5 & 0.56 & 67 & 17 & 23 & 2.91 & 74 & 159 & 2 & II \\
\hline J. G. & 57 & 3.5 & 0.35 & 73 & 14 & 29 & 4.24 & 143 & 152 & 2 & II \\
\hline M. S. & 54 & 4.9 & 0.62 & 63 & 17 & 22 & 2.49 & 93 & 183 & 3 & II \\
\hline R. B. & 50 & 4.9 & 0.50 & 72 & 14 & 30 & 2.30 & 294 & 153 & 2 & II \\
\hline
\end{tabular}

\% FEV, percent of predicted $\mathrm{FEV} ; \mathrm{Pa}_{2}$, arterial oxygen tension; PWP, pulmonary capillary wedge pressure; PAP, mean pulmonary artery pressure; CI, cardiac index; PVR, pulmonary vascular resistance; PEV, pulmonary extravascular water volume (normal $=120$ ); Clinical class, clinical classification of severity, as explained in the text; Radiological class, radiological evidence for pulmonary congestion, as explained in the text. 
TABLE V

Correlation Coefficients

\begin{tabular}{|c|c|c|c|c|c|c|c|c|c|c|c|c|c|}
\hline & $\begin{array}{l}\text { Chest } \\
\text { X-ray }\end{array}$ & $\begin{array}{l}\text { Clinical } \\
\text { class }\end{array}$ & PVR & $\mathrm{CI}$ & PEV & PAP & PWP & $\mathrm{PaO}_{2}$ & FDI & $\mathbf{R}_{\mathbf{3}}$ & $\mathbf{R}_{\mathbf{T}}$ & $\mathrm{FEF}_{2 b-76} \%$ & $\begin{array}{c}\% \\
\text { FEV }_{1} / \\
\text { FEV }\end{array}$ \\
\hline$\%$ Predicted FEV & $-0.72 \ddagger$ & $-0.68 *$ & -0.40 & +0.27 & +0.32 & $-0.81 \ddagger$ & $-0.89 \ddagger$ & +0.14 & $-0.60^{*}$ & $-0.76 t$ & $-0.71 \ddagger$ & $+0.86 t$ & +0.37 \\
\hline$\% \mathrm{FEV}_{1} / \mathrm{FEV}$ & -0.12 & -0.16 & $-0.82 \ddagger$ & +0.26 & +0.19 & -0.23 & -0.29 & -0.32 & -0.12 & -0.21 & -0.24 & +0.52 & \\
\hline $\mathrm{FEF}_{26-76} \%$ & $-0.72 \ddagger$ & $-0.62 *$ & -0.26 & +0.19 & +0.42 & $-0.59 *$ & $-0.70^{*}$ & +0.06 & $-0.56^{*}$ & $-0.62 *$ & $-0.56^{*}$ & & \\
\hline $\mathbf{R} \mathbf{T}$ & +0.48 & +0.46 & +0.21 & -0.34 & -0.05 & $+0.73 \ddagger$ & $+0.72 \ddagger$ & -0.45 & $+0.66^{*}$ & $+0.92 \ddagger$ & & & \\
\hline $\mathbf{R}_{\mathbf{z}}$ & +0.49 & $+0.63^{*}$ & +0.28 & -0.20 & -0.14 & $+0.85 \ddagger$ & $+0.78 \ddagger$ & -0.53 & $+0.89 \ddagger$ & & & & \\
\hline FDI & 0.31 & $+0.65^{*}$ & +0.12 & +0.07 & -0.24 & $+0.77 \ddagger$ & +0.48 & -0.49 & & & & & \\
\hline $\mathrm{PaO}_{2}$ & -0.48 & -0.08 & +0.30 & +0.34 & -0.37 & -0.32 & +0.20 & & & & & & \\
\hline PWP & +0.50 & $+0.77 \ddagger$ & +0.23 & -0.29 & -0.25 & $+0.81 \ddagger$ & & 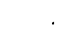 & & & & . & \\
\hline PAP & +0.52 & +0.48 & $+0.65^{*}$ & -0.05 & -0.36 & & & & & & & & \\
\hline PEV & -0.23 & -0.16 & -0.01 & -0.20 & & & & & & & & & \\
\hline $\mathrm{CI}$ & -0.50 & +0.01 & -0.23 & & & & & & & & & & \\
\hline PVR & +0.08 & +0.14 & & & & & & & & & & & \\
\hline Clinical class & +0.31 & & & & & & & & & & & & \\
\hline
\end{tabular}

Legends as in Tables I, II, and IV. Chest X-ray: radiological evidence for pulmonary congestion as explained in the text.

$*=\mathrm{p}<0.05$.

$\ddagger=\mathrm{p}<0.01$

$\mathrm{FEF}_{25-75 \%}$, pulmonary resistance at $3 \mathrm{cycle} / \mathrm{s}$, FDI and pulmonary wedge pressure was significant (Table V). The chest $\mathrm{X}$-ray signs of pulmonary congestion had positive correlations with the FEV and $\mathrm{FEF}_{25-\pi \%} \%$ but not with other parameters.

Control measurements. Values for FEV and its subdivisions obtained in the 15 control subjects were compared to the values reported by Morris, Koski, and
Johnson (Table VI). In general, our control subjects tended to have values 3-5 percentage points lower. This difference may be related to the standing position and the exclusion of smokers in the series reported by Morris and co-workers.

\section{DISCUSSION}

These studies demonstrate that during the first few days after acute myocardial infarction, most patients

TABLE VI

FEF and Pulmonary Resistance in Control Subjects and Patients with Arteriosclerotic Heart Disease

\begin{tabular}{|c|c|c|c|c|c|c|c|c|c|}
\hline Subjects & Age & $\%$ FEV & FEF $_{2 b-76} \%$ & RREs & $\mathbf{R}_{\mathbf{8}}$ & $\mathbf{R}_{\mathbf{b}}$ & $\mathbf{R}_{\mathbf{7}}$ & $\mathbf{R}_{\mathbf{0}}$ & FDI \\
\hline Normals & & & \multicolumn{7}{|c|}{$\mathrm{cm} \mathrm{H} \mathrm{H}_{2} \mathrm{O} /$ liler $/ \mathrm{s}$} \\
\hline R. H. & 41 & 93 & 100 & 1.1 & 1.2 & 1.1 & 1.1 & 1.0 & 0.03 \\
\hline M. G. & 30 & 100 & 100 & 1.4 & 1.3 & 1.4 & 1.4 & 1.4 & 0.00 \\
\hline S. D. & 37 & 105 & 110 & 1.8 & 1.9 & 1.8 & 1.7 & 1.6 & 0.03 \\
\hline V. D. & 47 & 95 & 100 & 1.6 & 1.9 & 1.6 & 1.6 & 1.6 & 0.08 \\
\hline M. G. & 58 & 92 & 90 & 1.6 & 1.8 & 1.6 & 1.6 & 1.4 & 0.07 \\
\hline P. B. & 43 & 95 & 80 & 2.0 & 2.1 & 2.0 & 1.9 & 1.9 & 0.03 \\
\hline D. B. & 38 & 100 & 90 & 1.3 & 1.5 & 1.3 & 1.2 & 1.2 & 0.05 \\
\hline B. C. & 32 & 90 & 92 & 1.4 & 1.5 & 1.4 & 1.4 & 1.4 & 0.03 \\
\hline J. C. & 54 & 93 & 98 & 1.6 & 1.8 & 1.6 & 1.6 & 1.6 & 0.07 \\
\hline J. V. & 47 & 92 & 90 & 1.8 & 1.9 & 1.8 & 1.8 & 1.7 & 0.03 \\
\hline Mean & 43 & 95 & 95 & 1.6 & 1.7 & 1.6 & 1.5 & 1.5 & 0.05 \\
\hline \multicolumn{10}{|c|}{ ASHD patients } \\
\hline D. A. & 37 & 87 & 80 & 1.6 & 1.8 & 1.6 & 1.6 & 1.4 & 0.05 \\
\hline R. K. & 42 & 100 & 100 & 1.4 & 1.5 & 1.4 & 1.4 & 1.2 & 0.03 \\
\hline J. C. & 50 & 92 & 88 & 2.0 & 2.2 & 2.2 & 2.0 & 2.0 & 0.05 \\
\hline H. D. & 62 & 82 & 75 & 2.0 & 2.3 & 2.0 & 2.0 & 1.6 & 0.07 \\
\hline M. F. & 62 & 88 & 88 & 1.4 & 1.6 & 1.5 & 1.4 & 1.4 & 0.05 \\
\hline Mean & 50 & 90 & 86 & 1.7 & 1.9 & 1.7 & 1.7 & 1.5 & 0.05 \\
\hline
\end{tabular}

\% FEV, percent of predicted $\mathrm{FEV} ; \mathrm{FEF}_{25-75 \%}$, percent of predicted $\mathrm{FEF}_{25-75 \%} ; \mathrm{R}_{\mathrm{RES}}$, pulmonary resistance measured at resonance; $R_{3}, R_{5}, R_{7}, R_{9}$, resistance measured at $3,5,7$, and 9 cycle/s. 
have a small but reversible abnormality in pulmonary mechanics. Typically, FEV and $\mathrm{FEV}_{1}$ are reduced $30 \%$, maximum $\mathrm{FEF}_{25-75} \%$ is reduced $40 \%$, and $\mathrm{R}_{\mathrm{RES}}$ is elevated $50 \%$. Similar findings have been reported by others $(1,6,22)$.

An original and more striking finding was the transient development of frequency dependence of $R_{T}$ (Table III, Fig. 4). For example, compared to measurements $2-3$ wk after acute myocardial infarction, $R_{s}$ was initially increased $115 \%$, while at 9 cycle/s, resistance was increased only $50 \%$. The following mechanisms deserve special attention as causes for these changes in lung function.

Decrease in lung volume. A decrease in lung volume will produce diminution of flow rates, increased $R_{T}$, and frequency dependence of lung compliance $(14,23,24)$. Since frequency dependence of compliance and resistance are closely related phenomena (Fig. 2), a decrease in lung volume would explain the development of frequency dependence of resistance in patients with acute myocardial infarction. Previous studies by other investigators have also noted a decrease in vital capacity with acute myocardial infarction and pulmonary congestion, so that this volume loss might explain the decrease in FEF $(1,11)$. However, $R_{T}$ is measured at functional residual capacity (FRC) or a volume slightly higher than FRC. Unfortunately, FRC was not measured in these patients, and measurements published by others do not clearly indicate if FRC increases or decreases with pulmonary congestion (25-27). We therefore cannot exclude the possibility that the development of frequency dependence of resistance was secondary to a decrease in lung volume.

According to the data of Fisher, DuBois, and Hyde, the $60 \%$ rise in $\mathrm{R}_{\mathrm{T}}$ such as observed in our patients would require a $40 \%$ decrease in FRC if the change was entirely due to a loss in volume (14). Such a large reduction in FRC seems unlikely. We therefore conclude that the elevated $R_{T}$ in acute myocardial infarction cannot be attributed solely to volume loss.

Bronchial constriction of major airways. Narrowing of major airways such as seen in bronchial asthma could account for the fall in FEF and the rise in $R_{T}$ ("cardiac asthma"). Bronchoconstriction of larger airways may increase lung volumes due to air trapped behind the site of constriction and may cause large increments in measured airway resistance, because these airways contain the major share of the resistance of airflow in the lungs $(28,29)$. This mechanism was not supported by the finding that the rise in $R_{T}$ was small compared to the changes seen in bronchial asthma (30). In addition, these subjects did not show any change in flow rates or $R_{T}$ after inhaling isoproterenol. Since the bronchoconstriction of asthma usually responds to this therapy, the lack of response to isoproterenol in our patients suggests that the mechanisms causing bronchoconstriction in patients with asthma does not commonly cause the decrease in flow rates or increase in $R_{T}$ observed in acute myocardial infarction.

Gravitational changes in pulmonary compliance and resistance. Regional changes in compliance or resistance due to gravitational forces could explain the development of frequency dependence of airway resistance (29). Lung compliance decreases with pulmonary congestion and this decrease is probably greater in dependent zones where pathological changes are more marked $(22,31)$. However, the degree of change reported in the dependent areas $(6,32)$ is probably not large enough to explain the degree of frequency dependence of pulmonary resistance observed in our subjects. For example, as shown in Fig. 2, when the time constants of a lung with two compartments differ by a factor of 40 , pulmonary resistance increases only twofold when the frequency is decreased from $10 \mathrm{cycle} / \mathrm{s}$ to $3 \mathrm{cycle} / \mathrm{s}$. We have made additional calculations using the equations of Otis, et al. (18), and they indicate that time constants of a two-compartment lung must usually differ by more than 10-fold to result in a $15 \%$ decrease in pulmonary resistance between 3 and $10 \mathrm{cycle} / \mathrm{s}$. Since external scanning techniques of the lungs after acute myocardial infarction have not demonstrated alterations in ventilation suggestive of this degree of abnormality, additional mechanisms must be contributing to the observed frequency dependence of pulmonary resistance in this disease $(6,32)$.

Peripheral airway disease. Macklem and Mead have shown that in human and canine lungs, airways smaller than $2 \mathrm{~mm}$ in diameter contribute less than $20 \%$ of the resistance to air flow in the lungs (28). This anatomical relationship permits considerable obstruction to air flow in the peripheral airways with little effect on $R_{\mathbf{T}}$. Airway obstruction in this location has been called disease in the "silent zone" of the lung, because there can be extensive peripheral airway obstruction with little change in total airway resistance or pulmonary resistance (33). Measurements other than airway or pulmonary resistance may be more sensitive in detecting peripheral airway obstruction. The development of frequency dependence of pulmonary resistance during acute myocardial infarction with only moderate rise in total pulmonary resistance is highly suggestive of alterations in peripheral airways $(29,34)$. Other techniques that would be expected to detect peripheral airway obstruction include fractionation of pulmonary resistance with catheters placed in airways of various sizes (28), partitioning the distribution of ventilation using nitrogen washout curves (35), measurement of the lung volume at which airways close (36), and 
demonstration of uneven time constants in the airways by determining the change in lung compliance at different frequencies (37). If the frequency dependence of resistance observed in this study is due to peripheral airway obstruction, these methods would probably demonstrate abnormalities in many patients with acute myocardial infarction. However, at the present time, to our knowledge, detailed studies of this nature have not been performed.

Factors resulting in changes in the mechanical properties of the peripheral airways have recently been reviewed in detail $(29,38)$. In addition to regional alterations in ventilation, pulmonary congestion has been shown to result in closure of collateral channels of ventilation between pulmonary segments in dogs (39). Anatomic studies show that pulmonary congestion widens the alveolar walls so that the pores of Kohn would probably be closed (31). Therefore, partially obstructed airways dependent upon collateral channels for adequate ventilation may become underventilated in the presence of pulmonary congestion due to closure of these collateral channels. The resultant alteration in airway time constants could account for the frequency dependence of pulmonary resistance seen in our subjects.

Recent studies in dogs with developing pulmonary edema, in which peripheral airway resistance was measured, demonstrated a rise in peripheral resistance which was most marked at low lung volumes (40). Morphological studies in the same animals suggested that competition for space between arteries and small airways in the bronchovascular sheath accounted for the rapidly reversible increase in peripheral resistance observed at elevations of left atrial pressure up to 15 $\mathrm{mm} \mathrm{Hg}$. At higher left atrial pressures, elevation in peripheral resistance was "irreversible" and was attributed to interstitial and alveolar edema. Peribronchial edema with resultant narrowing of the airways in the bronchovascular sheath is a likely additional mechanism. These pathophysiological processes would be expected to result in uneven time constants in the peripheral airways and would cause the alterations in pulmonary mechanics seen in pulmonary congestion after acute myocardial infarction.

Interdependence of airways. Recent studies have demonstrated that the uniform distribution of airflow within the lungs is assisted by interdependence of airways, so that a unit with compromised structure maintains reasonably normal ventilation because of the tethering effects of its normal neighbors (41). Pulmonary congestion and pulmonary edema could alter interdependence and thereby produce frequency dependence of pulmonary resistance. However, we are unaware of any attempt to determine the effect of pulmonary congestion on interdependence of airways.

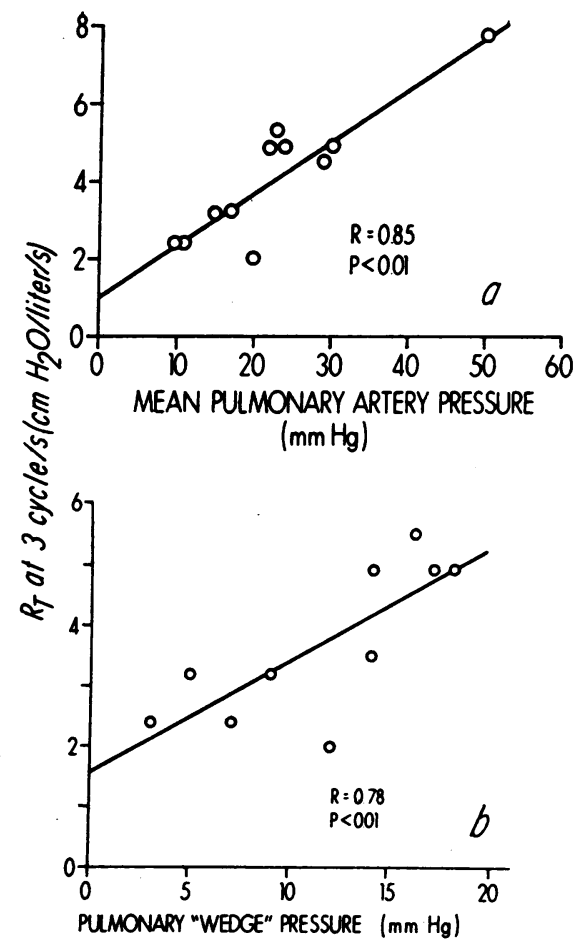

FIGURE 8 Correlation between $\mathrm{R}_{\mathbf{s}}$ and $(a)$ mean pulmonary artery pressure and $(b)$ pulmonary wedge pressure.

Relationship between alterations in hemodynamics and pulmonary function. Table $\mathrm{V}$ and Fig. 8 show that the development of elevated values of both $R_{s}$ and $R_{R E s}$ had a highly significant correlation with elevation of the pulmonary artery pressure and pulmonary capillary wedge pressure. The FDI significantly correlated with pulmonary artery pressure but not with the wedge pressure. These findings support the conclusion that the elevated vascular pressures account at least in part for the abnormal values of $R_{T}$. It is tempting to recommend determination of $R_{3}$ and $R_{R E s}$ or the FDI as a noninvasive method of detecting elevations of pulmonary vascular pressures. Such an application would be limited by the fact that early chronic obstructive pulmonary disease, hypoalbuminemia, and acute bronchiolitis are among diseases that show or would be expected to show elevated value of $R_{T}$ at $3 \mathrm{cycle} / \mathrm{s}$ and an abnormal amount of frequency dependence of resistance $(34,37,42)$. These diseases would therefore give false positive results. However, normal values for resistance and the FDI may be of value in excluding the diagnosis of elevated pulmonary vascular pressures. Studies in a larger series of patients with different causes of elevated pulmonary vascular pressures would be required in order to determine the usefulness of this application of resistance measurements. 
Pulmonary extravascular water volume. The poor correlation between pulmonary extravascular water volume and other pulmonary and hemodynamic data was somewhat surprising. Determinations of pulmonary extravascular volume in animals indicate that the percent of total lung water measured by this method varies considerably with the mechanism used to induce pulmonary congestion (43). Also, occlusion of pulmonary vessels decreases the observed pulmonary extravascular water volume (44). Since patients with acute myocardial infarction and pulmonary congestion may stop perfusing parts of their lungs due to perivascular cuffing or other mechanisms, it is not surprising that the values of pulmonary extravascular water volume are at times lower than expected.

Hypoxia and $R_{T}$. The development of frequency dependence of resistance and elevated values of $R_{T}$ in acute myocardial infarction would be expected to cause uneven distribution of ventilation to perfusion and arterial hypoxia. The arterial $\mathrm{Po}_{2}$ should, therefore, closely correlate with $\mathrm{R}_{\mathbf{T}}$ and the FDI. However, even though $\mathrm{R}_{\mathrm{T}}$ and pulmonary vascular pressures tended to be higher in the more hypoxic patients, significant correlations between arterial $\mathrm{PO}_{2}$ and these parameters could not be demonstrated (Table V). Studies by Kazemi, Parsons, Valencia, and Strieder (6) may partly explain the failure to find a significant correlation between arterial hypoxia and these parameters. They performed regional studies of pulmonary ventilation and perfusion, and showed that regional ventilation-to-perfusion ratios are actually more uniform in patients with acute myocardial infarction than in normal subjects, because of diminished pulmonary blood flow in the dependent zones of the lung. Since hypoxia is an extremely common finding in acute myocardial infarction, this mechanism must only modify rather than prevent arterial hypoxia. Mismatching of ventilation to perfusion may still be present within the gross zones analyzed by external scanning techniques. In addition, regional hypoxia, acidosis, or currently unidentified humoral or reflex mechanism may alter the airways and the pulmonary vasculature in a manner that tends to preserve normal distribution of ventilation to perfusion and thereby minimize arterial hypoxia (45).

Correlations with clinical and radiological findings. The clinical classification of the patients showed a significant correlation with pulmonary wedge pressure and many of the tests indicative of airway obstruction. This study, therefore, confirms the value of the physical examination in detecting the physiological abnormalities accompanying pulmonary congestion. Surprisingly, the signs of congestion demonstrated by the roentgenograms of the chest only correlated with FEV and $\left(\mathrm{FEF}_{25-75 \%}\right)$.
In contrast, McHugh and co-workers (12), in a study of 30 patients, found that the abnormalities on the chest X-rays suggestive of pulmonary congestion had a reasonable correlation with the pulmonary wedge pressure and the arterial $\mathrm{Po}_{2}$. However, they suggested that the roentgenographic abnormalities may develop and clear more slowly than the hemodynamic changes. The X-ray abnormalities could therefore be out of phase with the hemodynamic data, with a resultant poor correlation. In this study the failure to demonstrate a significant correlation between roentgenographic findings and many of the other parameters may be caused in part by this phase lag. In addition, in this study roentgenograms of the chest in only 10 patients were compared to the other indices, so that the sample size may have been too small to demonstrate a significant correlation.

Detection of peripheral airway disease. Most methods for diagnosing peripheral airway disease, such as radioactive gas techniques and measurements of lung compliance at different ventilatory frequencies, are either too complex or too uncomfortable to be suitable for wide clinical application. Determination of lung closing volumes by inspiring oxygen or a foreign gas circumvents many of the undesirable features of the other methods, but requires a carefully controlled ventilatory maneuver. The technique of determining $R_{T}$ at different frequencies used in this study avoids the need for special ventilatory maneuvers and uses relatively simple equipment. We have found this test to be a rapid and practical measurement in the study of a large number of ambulatory patients being screened for early obstructive lung disease. ${ }^{5}$ Comparative studies with other techniques in man and experimental animals are needed to see if determination of $\mathrm{R}_{\mathbf{T}}$ at different frequencies is a reliable method of detecting peripheral airway obstruction.

\section{ACKNOWLEDGMENTS}

We are indebted to Dr. Barry A. Gray for critical review of the manuscript.

This research was supported by grants-in-aid HL 03966, HL 05500, HL 10324, Contract no. NIH-PH-43-68-1331MIRU, National Heart and Lung Institute, National Institutes of Health, and the Atomic Energy Project at the University of Rochester, and has been assigned publication no. UR-3490-340.

\section{REFERENCES}

1. McNicol, M. W., B. J. Kirby, K. D. Bhoola, M. E. Everest, H. V. Price, and S. F. Freedman. 1970. Pulmonary function in acute myocardial infarction. $\mathrm{Br}$. Med. J. $2: 1270$.

${ }^{5}$ Hall, W. J., R. D. Webb, and R. W. Hyde. Unpublished data.

2004 B. Interiano, R. W. Hyde, M. Hodges, and P. N. Yu 
2. McNicol, M. W., B. J. Kirby, K. D. Bhoola, P. M. Fulton, and A. E. Tattersfield. 1966 Changes in pulmonary function 6-12 months after recovery from myocardial infarction. Lancet. $2: 1441$

3. Valentine, P. A., D. C. Fluck, J. I'. D. Mounsey, D. Reid, J. P. Shilling ford, and R. E. Steiner. 1966. Bloodgas changes after acute myocardial infarction. Lancet. $2: 837$.

4. MacKenzie, G. J., S. H. Taylor, D. C. Flenley, A. H. McDonald, H. P. Staunton, and K. W. Donald. 1964. Circulatory and respiratory studies in myocardial infarction and cardiogenic shock. Lancet. $2: 825$.

5. Shillingford, J. P., and M. Thomas. 1967. Cardiovascular and pulmonary changes in patients with myocardial in farction treated in an intensive care unit. $\mathrm{Am}$. J. Cardiol. 20: 484.

6. Kazemi, H., E. F. Parsons, L. M. Valencia, and D. J. Strieder. 1970. Distribution of pulmonary blood flow after myocardial ischemia and infarction. Circulation. 41: 1025 .

7. Storstein, O., and K. Rasmussen. 1968. The cause of arterial hypoxemia in acute myocardial infarction. Acta Med. Scand. 183 : 193.

8. Pain, M. C. F., M. Stannard, and G. Sloman. 1967. Disturbances of pulmonary function after acute myocardial infarction. Br. Med. J. 2: 591.

9. Fillmore, S. J., M. Shapiro, and T. Killip. 1970. Arterial oxygen tension in acute myocardial infarction. Serial analysis of clinical state and blood gas changes. Am. Heart J. 79 : 620.

10. Higgs, B. E. 1968. Factors influencing pulmonary gas exchange during the acute stages of myocardial infarction. Clin. Sci. (Oxf.). 35: 115 .

11. Valencia, A., and J. H. Burgress. 1969. Arterial hypoxemia following acute myocardial infarction. Circulation. 40: 641 .

12. McHugh, T. J., J. S. Forrester, L. Adler, D. Zion, and H. J. C. Swan. 1972. Pulmonary vascular congestion in acute myocardial infarction: Hemodynamic and radiologic correlations Ann. Intern. Med. 76: 29.

13. Morris, J. F., A. Koski, and L. C. Johnson. 1971. Spirometric standards for healthy nonsmoking adults. Am. Rev. Respir. Dis. 103: 57.

14. Fisher, A. B., A. B. DuBois, and R. W. Hyde. 1968. Evaluation of the forced oscillation technique for the determination of resistance to breathing. J. Clin. Invest. $47: 2045$.

15. Hyatt, R. E., I. R. Zimmerman, G. E. Peters, and W. J. Sullivan. 1970. Direct writeout of total respiratory resistance. J. Appl. Physiol. 28: 675.

16. Frank, N. R., J. Mead, and J. L. Whittenberger. 1971. Comparative sensitivity of four methods for measuring changes in respiratory flow resistance in man. J. Appl. Physiol. 31 : 934.

17. Goldman, M., R. J. Knudson, J. Mead, N. Peterson, J. R. Schwaber, and M. E. Wohl. 1970. A simplified measurement of respiratory resistance by forced oscillation. J. Appl. Physiol. 28: 113.

18. Otis, A. B., C. B. McKerrow, R. A. Bartlett, J. Mead, M. B. McIlroy, N. J. Salverstone, and E. P. Radford. 1956. Mechanical factors in distribution of pulmonary ventilation. J. Appl. Physiol. $8: 427$.

19. Gazioglu, K., J. J. Condemi, R. W. Hyde, and N. L. Kaltreider. 1971. Effect of isoproterenol on gas exchange during air and oxygen breathing in patients with asthma. Am. J. Med. 50: 185.

20. Swan, H. J. C., W. Ganz, J. Forrester, H. Marcus, G. Diamond, and D. Chonetti. 1970. Catheterization of the heart in man with use of a flow-directed balloontipped catheter. N. Engl. J. Med. $283: 447$.

21. Chinard, F. P. 1951. Capillary permeability. Bull. Johns Hopkins Hosp. 88: 489.

22. Sharp, J. T., G. T. Griffith, I. L. Bunnell, and D. G. Greene. 1958. Ventilatory mechanics in pulmonary edema in man. J. Clin. Invest. $37: 111$.

23. Hyatt, R. E., D. P. Schilder, and D. L. Fry. 1958. Relationship between maximum expiratory flow and degree of lung inflation. J. Appl. Physiol. 13: 131.

24. Mills, R. J., G. Cumming, and P. Harris. 1963. Frequency-dependent compliance at different levels of inspiration in normal adults. J. Appl. Physiol. 18: 1061.

25. Briscoe, W. A. 1965. Lung volumes. Handb. Physiol. 2 (Sect. 3 Respiration) : 1370.

26. Bedell, G. N., Y. Suzuki, and W. R. Wilson. 1961. Pulmonary abnormalities in congestive heart failure. J. Lab. Clin. Med. 58: 798. (Abstr.)

27. Peters, J. P., Jr., and D. P. Barr. 1920. Studies of the respiratory mechanisms in cardiac dyspnea. II. A note on the effective lung volume in cardiac dyspnea. $\mathrm{Am}$. J. Physiol. 54 : 335.

28. Macklem, P. T., and J. Mead. 1967. Resistance of central and peripheral airways measured by a retrograde catheter. J. Appl. Physiol. 22 : 395.

29. Macklem, P. T. 1971. Airway obstruction and collateral ventilation. Physiol. Rev. $51: 368$.

30. Butler, J., C. G. Caro, R. Alcala, and A. B. DuBois. Physiological factors affecting airway resistance in normal subjects and in patients with obstructive respiratory disease. J. Clin. Invest. 39 : 584.

31. Staub, N. C., H. Nagano, and M. L. Pearce. 1967. Pulmonary edema in dogs, especially the sequence of fluid accumulation in the lungs. J. Appl. Physiol. 22: 227.

32. Hughes, J. M. B., J. B. Glazier, D. Y. Rosenzweig, and J. B. West. 1969. Factors determining the distribution of pulmonary blood flow in patients with raised pulmonary venous pressure Clin. Sci. (Oxf.). 37: 847 .

33. Mead, J. 1970. The lung's quiet zone. N. Engl. J. Med. 282: 1318.

34. Grimby, G. T., T. Takishima, W. Graham, P. T. Macklem, and J. Mead. 1968. Frequency dependence of flow resistance in patients with obstructive lung disease. $J$. Clin. Invest. $47: 1455$.

35. Bouhuys, A. 1964. Distribution of inspired gas in the lungs. Handb. Physiol. 1(Sect. 3 Respiration) : 715.

36. Anthonisen, N. R., J. Danson, P. C. Robertson, and W. R. D. Ross. 1969. Airway closure as a function of age. Respir. Physiol. 8: 58.

37. Woolcock, A. J., N. J. Vincent, and P. T. Macklem. 1969. Frequency dependence of compliance as a test for obstruction in small airways. J. Clin. Invest. 48: 1097.

38. Milic-Emili, J., and F. Ruff. 1971. Effects of pulmonary congestion and edema on the small airways. Bull. Physio-Pathol. Respir. 7 : 1181.

39. Ankeney, J. L., C. A. Hubay, and F. W. Tillotson. 1950. The effect of changes in pulmonary circulation on collateral ventilation. Surg. Forum. 1: 25 
40. Hogg, J. C., J. B. Agarawal, A. J. S. Gardiner, W. H. Palmer, and P. T. Macklem. 1972. Distribution of airway resistance with developing pulmonary edema in dogs. J. Appl. Physiol. 32: 20.

41. Menkes, H., D. Lindsay, L. Wood, A. Muir, and P. T. Macklem. 1972. Interdependence of lung units in intact dog lungs. J. Appl. Physiol. 32 : 681.

42. Ruff, F., J. M. B. Hughes, N. Stanley, D. McCarthy, R. Greene, A. Aronoff, L. Clayton, and J. Milic-Emili.
1971. Regional lung function in patients with hepatic cirrhosis. J. Clin. Invest. 50: 2403.

43. Pearce, M. L., J. Yamashita, and J. Beazell. 1965. Measurement of pulmonary edema. Circ. Res. 16: 482.

44. Kirk, B. S. 1969. Effect of alteration in pulmonary blood flow on lung-exchangeable water in the dog. $J$. Appl. Physiol. $27: 607$.

45. Fishman, A. P. 1961. Respiratory gases in the regulation of the pulmonary circulation. Physiol. Rev. 41: 214. 